\title{
Cadastro Ambiental Rural utilizando imagem de drone aerofotogramétrico
}

João Edson Costa Ferreira da Silva ${ }^{1}$

Mosar Faria Botelho ${ }^{2}$

\section{Resumo}

O Cadastro Ambiental Rural (CAR) é uma importante base de dados estratégica para a gestão ambiental do país. Este estudo tem como objetivo comparar a acurácia da imagem orbital disponibilizada para o CAR com uma ortofoto obtida com o drone aerofotogramétrico, tendo como parâmetro de incerteza o produto cartográfico obtido com estação total. A ortofoto apresentou melhor resultado em relação à imagem orbital. Ambas foram analisadas comparando áreas homólogas nas imagens, de diferentes tamanhos e posições, em ambos os produtos cartográficos. Tal resultado pode justificar a aquisição de um produto mais fidedigno para o controle ambiental no país, principalmente em pequenas áreas rurais, tendo em vista que a porção territorial é extensa e não homogênea.

Palavras-chave: Fotogrametria aplicada. Imóvel rural. Meio ambiente.

\section{Introdução}

O Cadastro Ambiental Rural (CAR) é uma ferramenta da grande área geociências, fundamental para auxiliar no processo de regularização ambiental de propriedades e posses rurais. Consiste no levantamento de informações georreferenciadas do imóvel, com delimitação das Áreas de Proteção Permanente (APP), Reserva Legal (RL), área remanescente de vegetação nativa, área rural consolidada, áreas de interesse social e de utilidade pública, com o objetivo de traçar um mapa digital a partir do qual são calculados os valores das áreas para diagnóstico ambiental (BRASIL, 2015).

Até junho de 2015, mais de um milhão e meio de imóveis rurais já haviam sido cadastrados, totalizando uma área de 227.679.854 hectares, equivalentes a 57,27\% da área total rural brasileira, e inseridos na base de dados do sistema. Percebe-se um crescimento significativo nos cadastros; no entanto, devido à grande extensão territorial do país e à defasagem no cadastro rural, são necessárias medidas mais rápidas para o controle efetivo do meio ambiente. A Figura 1 mostra a relação das áreas cadastradas no Brasil.

\footnotetext{
1 Instituto Federal de Educação, Ciência e Tecnologia Sul de Minas Gerais, discente pesquisador. Inconfidentes, Minas Gerais, Brasil. joaoedsoncosta@hotmail.com Praça Tiradentes,416, Centro, Inconfidentes (MG), CEP: 37576-000.

2 Instituto Federal de Educação, Ciência e Tecnologia Sul de Minas Gerais, professor pesquisador. Inconfidentes, Minas Gerais, Brasil. mosar.botelho@ifsuldeminas.edu.br. Praça Tiradentes,416, Centro, Inconfidentes, MG, CEP: 37576-000.
} 
Figura 1. Boletim informativo, janeiro de 2016 (adaptada de Serviço Florestal Brasileiro, 2016)

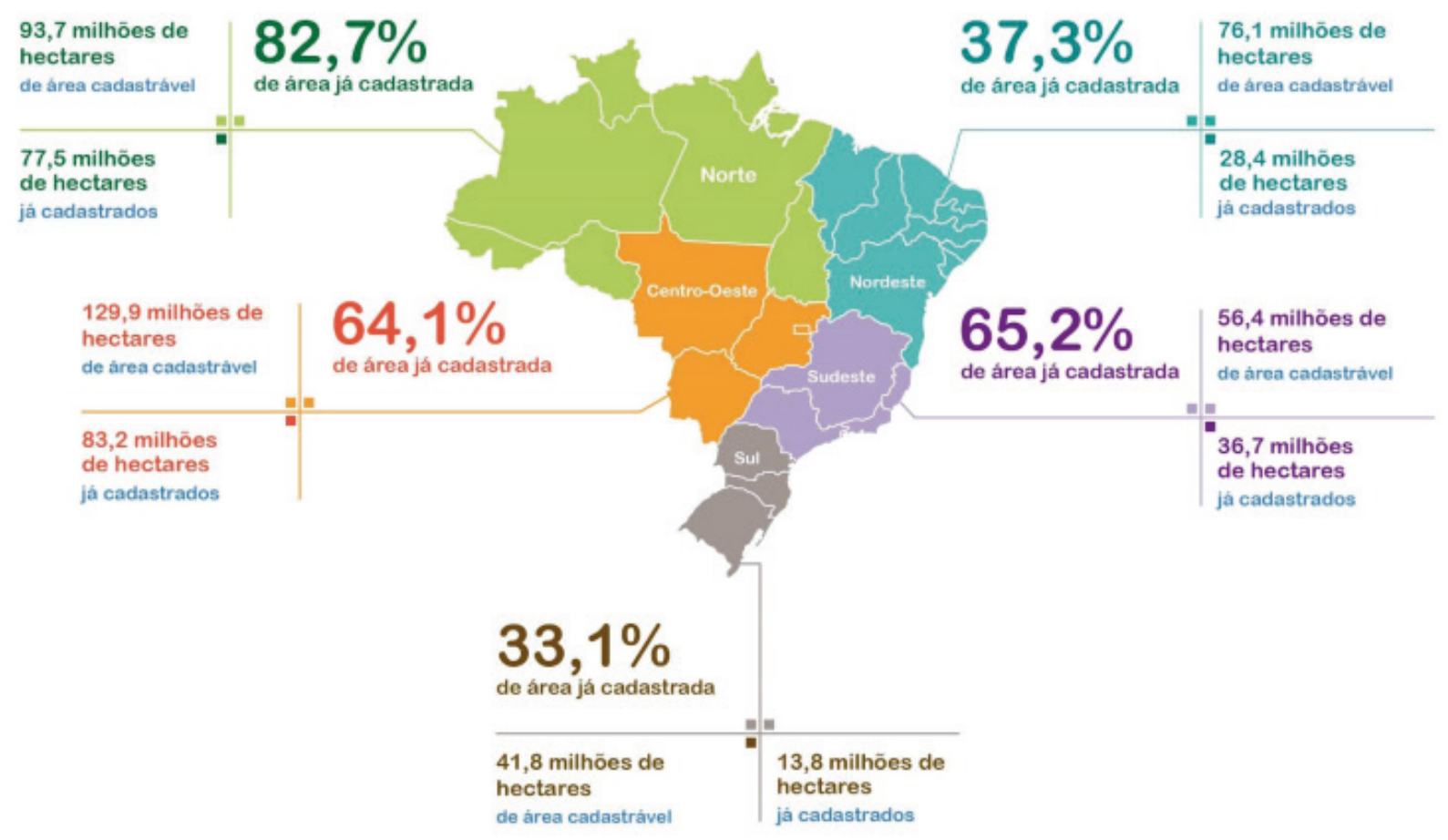

Fonte: Elaborada pelos autores

Outro ponto significativo é a maneira como o cadastro é realizado. Sabe-se que imagens de satélites possuem certas limitações, principalmente as que são disponibilizadas atualmente na plataforma offline do CAR. Nota-se que os parâmetros de resolução espacial, radiométrica e temporal são um tanto negligenciáveis no sistema/usuário. Essas imagens não possuem um tratamento científico adequado para análises mais fidedignas.

Um dos principais problemas ligados aos registros realizados no CAR é a fidedignidade das informações (Figura 1). Embora o cadastro tenha uma finalidade expedita, deve-se levar em consideração a acurácia das informações espaciais obtidas, pois elas são as fontes que determinarão a relação real entre o número de imóveis cadastrados e não cadastrados. A imagem apresentada no $\mathrm{CAR}$, quando comparada com uma foto obtida com uma tecnologia de inovação no mercado, drone aerofotogramétrico, apresenta dificuldade na identificação e limitação de áreas almejadas. Essas tecnologias aerotransportadas controladas remotamente apontam maior praticidade e precisão, podendo vir a ser tendência na obtenção de informações do uso do solo.

0 drone aerofotogramétrico tem como principal finalidade gerar um produto cartográfico que seja passível de obter análise de informações espaciais (qualitativas e quantitativas) com precisão, de forma rápida e remota. No entanto, devem ser tomados alguns cuidados na aquisição dessas imagens. Os principais cuidados são garantir a estabilidade e ortogonalidade da câmera em relação ao solo e a qualidade e recobrimento entre as imagens sucessivas.

O presente estudo tem como objetivo avaliar a acurácia da imagem disponibilizada para o CAR em comparação à ortofoto obtida com o drone aerofotogramétrico, tendo como base de apoio geodésico pontos de controle existentes na área de estudo. Como indicador de validação, foi utilizado o Root Mean Square (RMS), raiz do valor médio quadrático, que pode ser definido como a média das diferenças entre o valor estimado e o valor observado para cada um dos pontos de controle no terreno. 


\section{Materiais e métodos}

A propriedade rural, local do estudo, está situada no município de Inconfidentes (MG), nas seguintes coordenadas geográficas: Latitude $22^{\circ} 19^{\prime} 48^{\prime \prime}$ Sul e Longitude $46^{\circ} 20^{\prime} 00^{\prime \prime}$ Oeste, com área aproximada de 10,4 hectares. A escolha de tal propriedade se caracteriza pelo apoio oferecido pelo proprietário Flávio Garcia Reberte, bem como a existência de pontos (marcos) georreferenciados (Figura 2).

Figura 2. Mapa de situação da área de estudo (adaptado de Google Earth Pro, 2016)

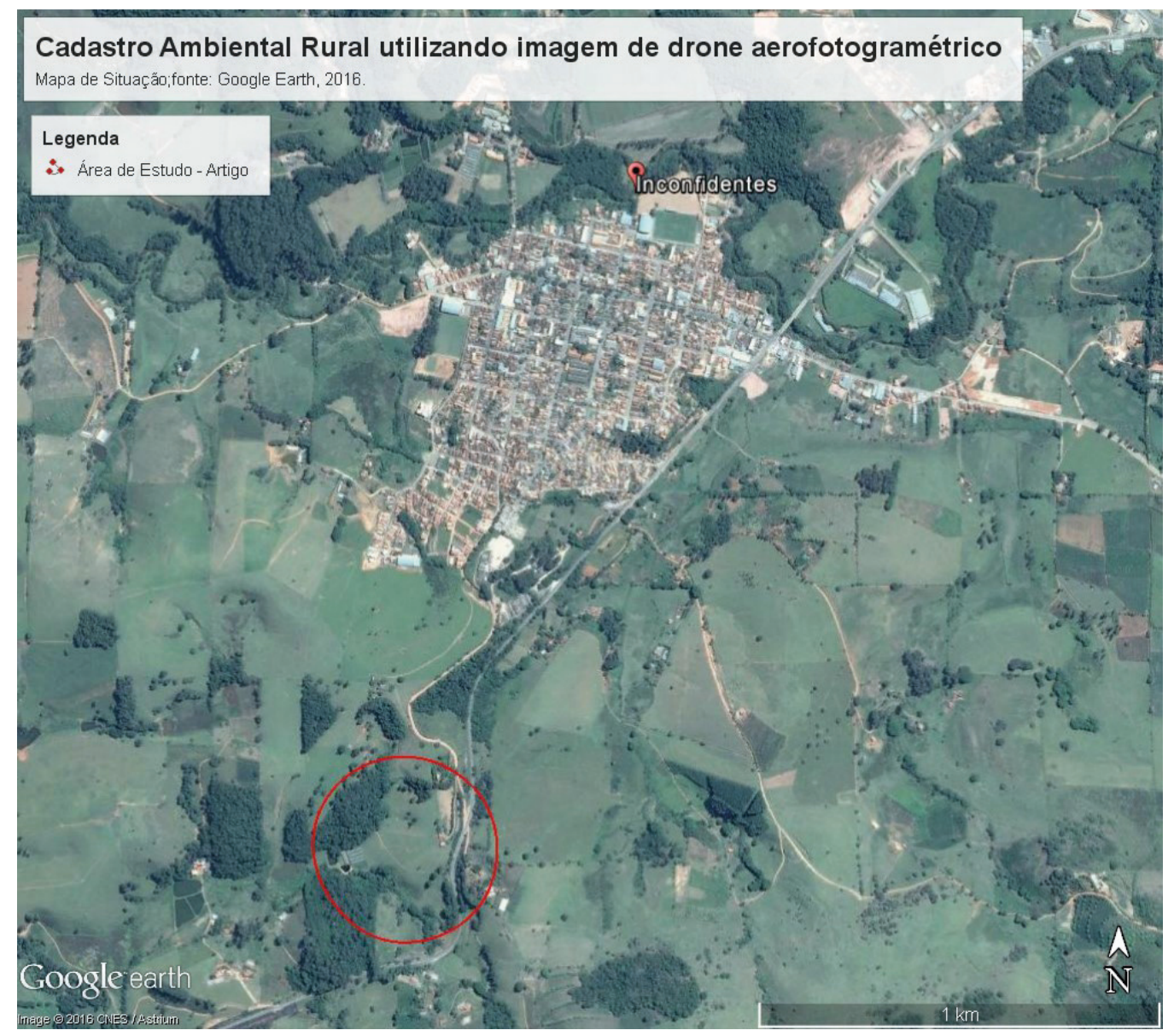

Fonte: Elaborada pelos autores, via Google Earth (2016)

Após o reconhecimento da área, inicia-se o processo do plano de voo, que tem como objetivo propiciar um planejamento sobre as características do produto cartográfico que se deseja obter. Executou-se um plano de voo manual, o qual determinou a direção do voo (sentido) e altura de voo, para que se obtivesse um produto com as características de interesse. Para tanto, utiliza informações como altitudes médias do terreno (disponíveis no Google Earth) e os parâmetros da câmera (tamanho do CCD, resolução e distância focal). Ao final do processo, obteve-se um Ground Sample Distance (GSD), tamanho do pixel no terreno, de 0,609 m para uma altura de voo de $118 \mathrm{~m}$.

Foram utilizados alvos artificiais e naturais para o controle do produto cartográfico gerado pelas imagens. Tais pontos foram determinados a partir das coordenadas dos marcos de apoio geodésico existentes.

Utilizou-se de uma estação total modelo Leica TS02 (Precisão Linear: 1,5 mm+ 2 ppm; Precisão Angular: 3") para o levantamento das coordenadas dos pontos de controle para o transporte de coordenadas e das áreas de comparação. No levantamento foi realizada a técnica de poligonação 
clássica; utilizando 5 pontos, obteve-se um erro relativo na ordem de 1/35.000, erro angular na poligonal de 00'9,4" e linear de 0,032 m. Para o processamento dos dados foi utilizado o Software Topograph 98 SE, os dados foram ajustados utilizando o Método dos Mínimos Quadrados (MMQ). No presente estudo, os dados foram utilizados sobretudo para a correção geométrica da ortofoto e como parâmetro de comparação entre as áreas em estudo.

Os pontos de controle têm como objetivo permitir que haja transformações do sistema fotográfico (pixel) para o sistema métrico (coordenadas cartesianas). Tal transformação é chamada de orientação interior. De acordo com Coelho e Brito (2009), por orientação interior entende-se a reconstrução do feixe perspectivo, ou seja, o referenciamento da imagem em relação à câmera. Em trabalhos de fotogrametria digital, costuma-se usar como validação de produto cartográfico a correção geométrica da imagem, a fim de minimizar erros sistemáticos provenientes das limitações das câmeras não métricas, como neste caso.

Após a distribuição dos pontos de controle, inicia-se o processo de obtenção das imagens. As imagens orbitais são obtidas pela plataforma http://www.car.gov.br/(Figura 3). Essas imagens são passíveis de correção; no entanto, neste trabalho são vistas como objetos de estudo, o que justifica a não realização da correção geométrica dessas. No sistema não são divulgados os parâmetros, bem como as precisões das imagens, fato que nos fez utilizar os dados comparativos de área da própria plataforma.

Figura 3 - Plataforma SISCAR
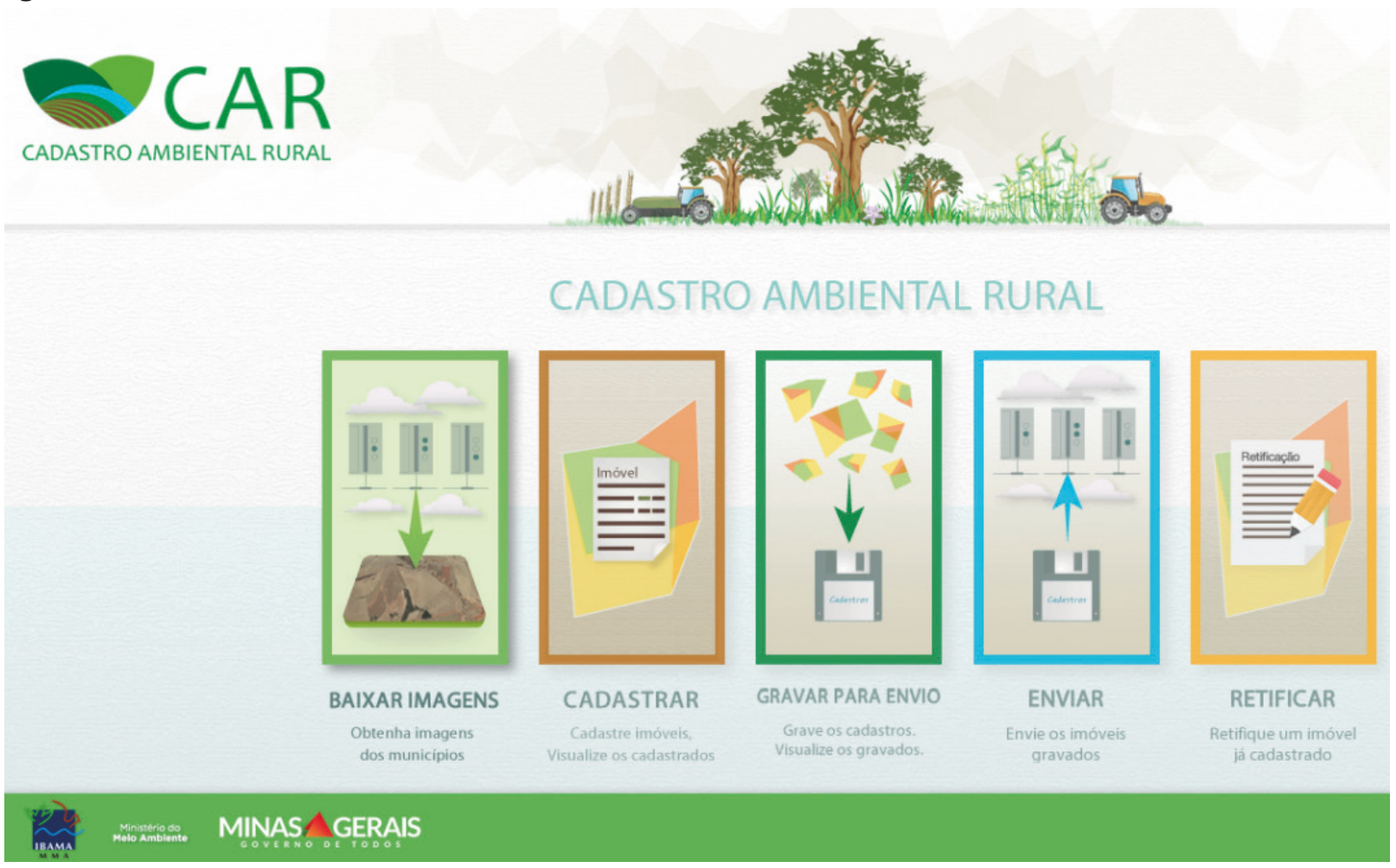

Fonte: Plataforma do SISCAR (2016)

As fotos aéreas foram obtidas por meio do hexacóptero (drone) modelo DJI F550, tendo a bordo um conjunto fotogramétrico de precisão, contendo a câmera não métrica GoPro HERO 3 + Black Edition, 12 megapixels, com seu respectivo gimbal, para mantê-la posicionada ortogonalmente em relação ao solo; Maleta First Person View (FPV) - visão em primeira pessoa, com monitor CCE 14"; Sensores Data Link/GPS NAZA V2, que quantificam velocidade e posição do drone em relação ao solo (Figura 4). 
Figura 4. Hexacóptero aerofotogramétrico

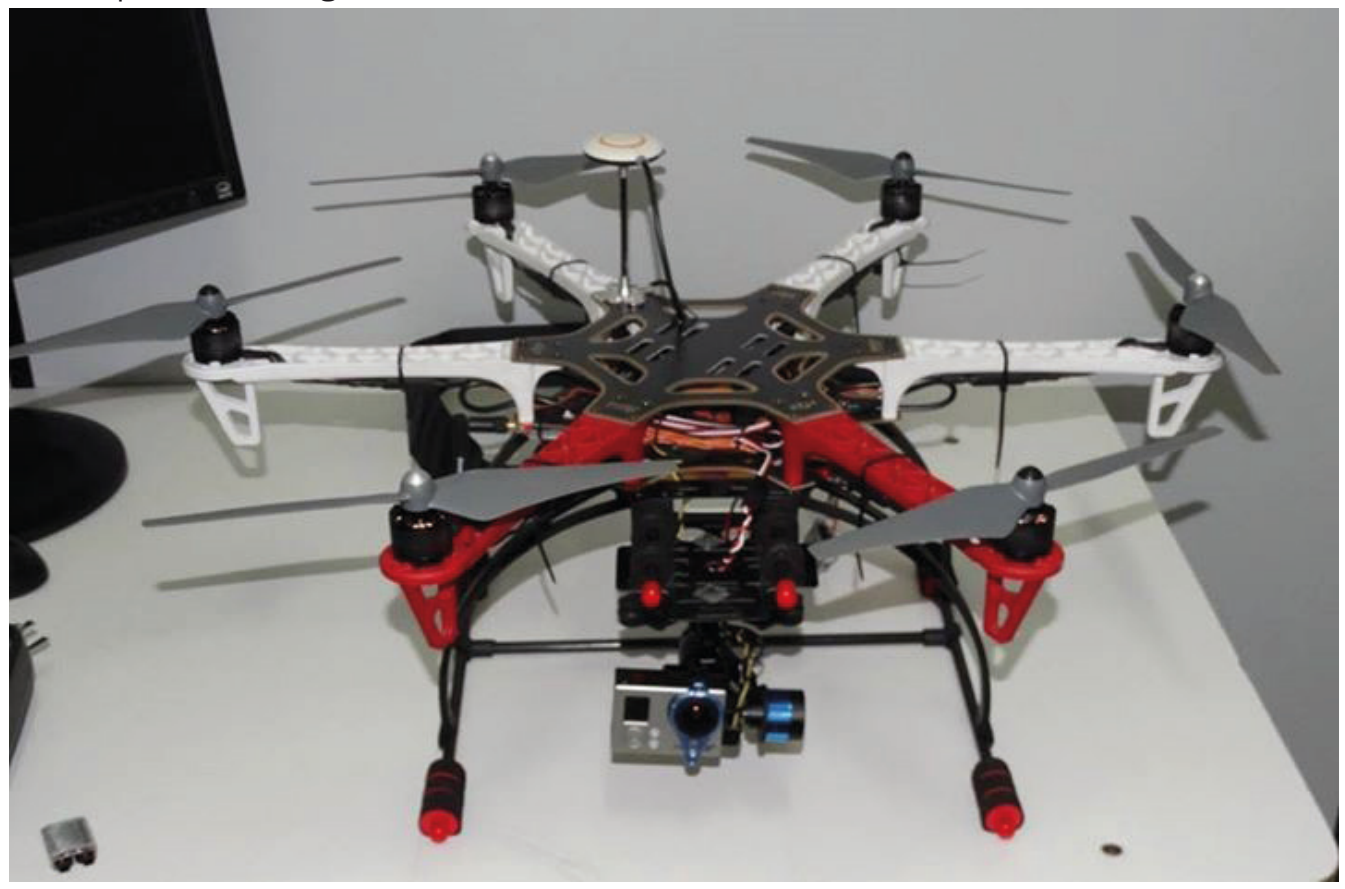

Fonte: Elaborada pelos autores

Obtém-se com o drone um conjunto de fotos sequenciais, com base nos parâmetros estabelecidos pelo plano de voo. Mantém-se durante todo o levantamento a visão FPV. A altura de voo foi de $118 \mathrm{~m}$ contados a partir da elevação média do terreno. O drone se manteve a uma velocidade de $14 \mathrm{~m} / \mathrm{s}$, com aquisição de fotografia de 5 em 5 segundos, programadas previamente na câmera GoPro. Esses fatores permitem uma maior precisão na obtenção das imagens, pois torna-se possível ter uma visão da área de mapeamento, bem como o estado (posição e velocidade) em que o objeto se encontra no momento da aquisição da foto.

No processamento das imagens foi utilizado o software Adobe Photoshop LightRoom versão 5.7.1 para retirar o efeito fish eye (olho de peixe), proveniente da câmera GoPro utilizada. Com o objetivo de reduzir a área de interesse para a parte central da imagem, de modo a evitar as distorções radiais simétrica e descentrada que existem sobre as imagens, foi realizado um redimensionamento de $150 \%$ da imagem, mantendo o seu tamanho original, ou seja, realizou-se um recorte em seu centro.

De acordo com Andrade (1998), a distorção radial simétrica pode ser entendida como sendo a parcela não desejável da refração sofrida por um raio de luz ao atravessar uma lente. A distorção descentrada, que é resultante das parcelas de distorções tangencial e radial assimétrica, está relacionada com a impossibilidade de alinhar perfeitamente os eixos ópticos das lentes que formam a objetiva.

Segundo Brown (1966), a distorção descentrada pode ser calibrada analiticamente, bem como a distorção radial simétrica (Brown,1956), incorporando o modelo matemático para descentrar a distorção nas equações projetivas originais geradas por medições de placa (quadro ou placa de calibração). Para este trabalho não foi realizada uma prévia calibração da câmera utilizada. Foi deixado a encargo do software Agisoft PhotoScan versão 1.1.5 determinar automaticamente os parâmetros de calibração da câmera.

As imagens são adicionadas ao software Agisoft PhotoScan versão 1.1.5 para o processo de fototriangulação, mosaicagem e geração de ortofoto. Nos processos fotogramétricos que envolvem a geração da ortofoto, torna-se cabível o cuidado para a inserção de imagens que atendam aos requi- 
sitos básicos da fotogrametria, como recobrimento longitudinal de 60\% e lateral de 30\%. Também deve se atentar a possíveis falhas da câmera no momento da aquisição das imagens, de modo que as imagens não estejam comprometidas com "arrastes" e "borrões".

0 produto cartográfico final gerado pelo processamento é a ortofoto digital (Figura 5). Essa é uma projeção ortogonal de um conjunto de fotos obtidas com o objetivo de minimizar distorções e aderir poder cartográfico, inerente a um mapa para o usuário.

Figura 5. Ortofoto digital da propriedade.

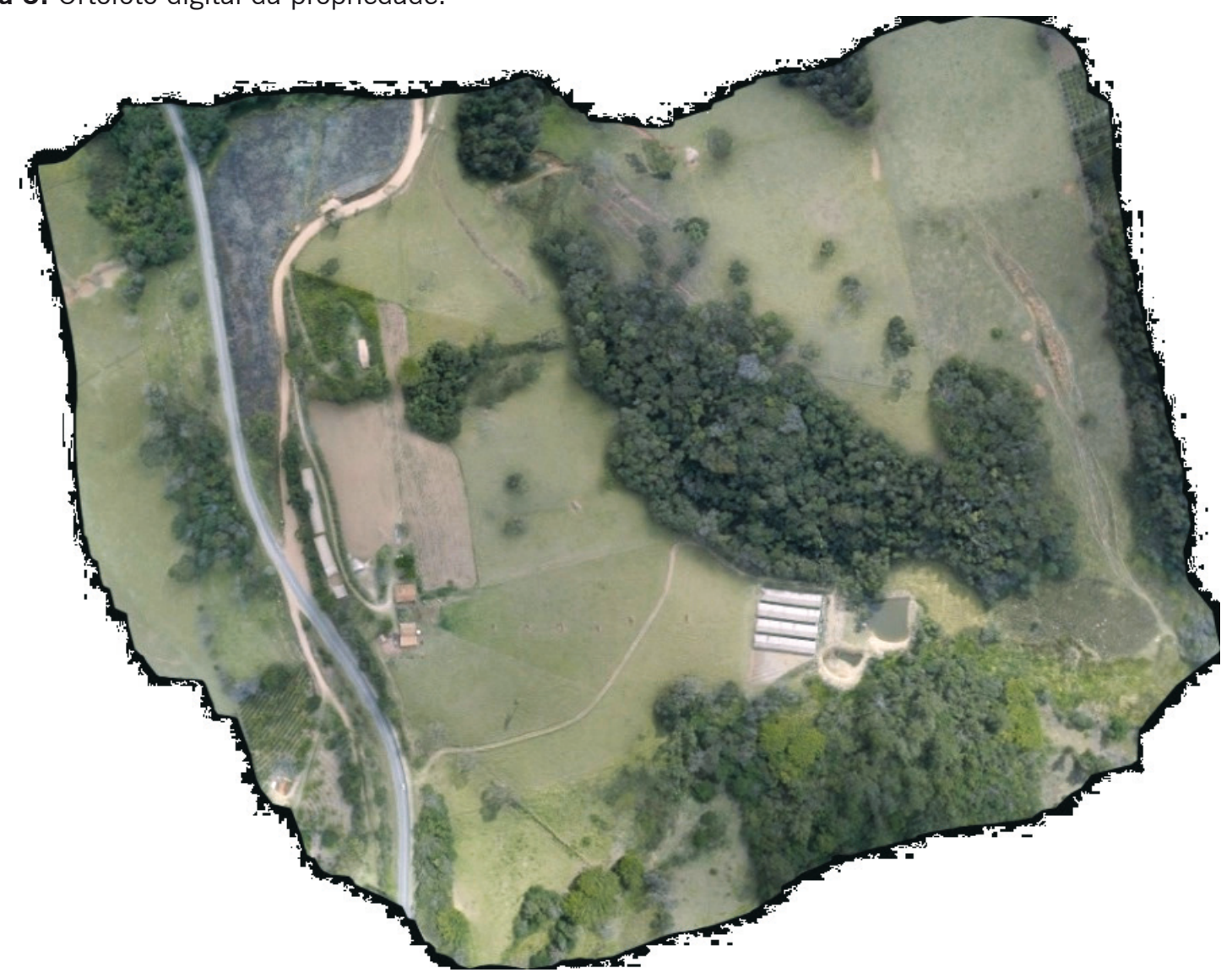

Fonte: Autor (2016)

A ortofoto gerada não está em um sistema métrico e sim fotográfico, logo sua correção geométrica foi executada de modo a corrigir esse problema e também validar o produto obtido, utilizando o software ENVI 4.7 para tal realização. Como parâmetro de análise foi considerado o RMS.

O RMS é a equação matemática de validação do produto cartográfico gerado, definido pela Equação 1:

$$
\mathrm{RMS}=\sqrt{\frac{1}{n} \sum_{i=1}^{n}\left(x_{i}-\bar{x}\right)^{2}}
$$

Em que: $\mathrm{N}$ é o número de amostras, Xi é o valor fornecido pelo classificador para a i-ésima amostra e $\mathrm{X}$ é a média dos valores de todas as amostras.

No processamento da correção geométrica da ortofoto, de acordo com a Tabela 1, obteve-se um RMS de 2,5809 pixels para 6 pontos espalhados de forma homogênea na imagem (Figura 6). 
Figura 6. Imagem corrigida com respectiva distribuição espacial dos pontos.

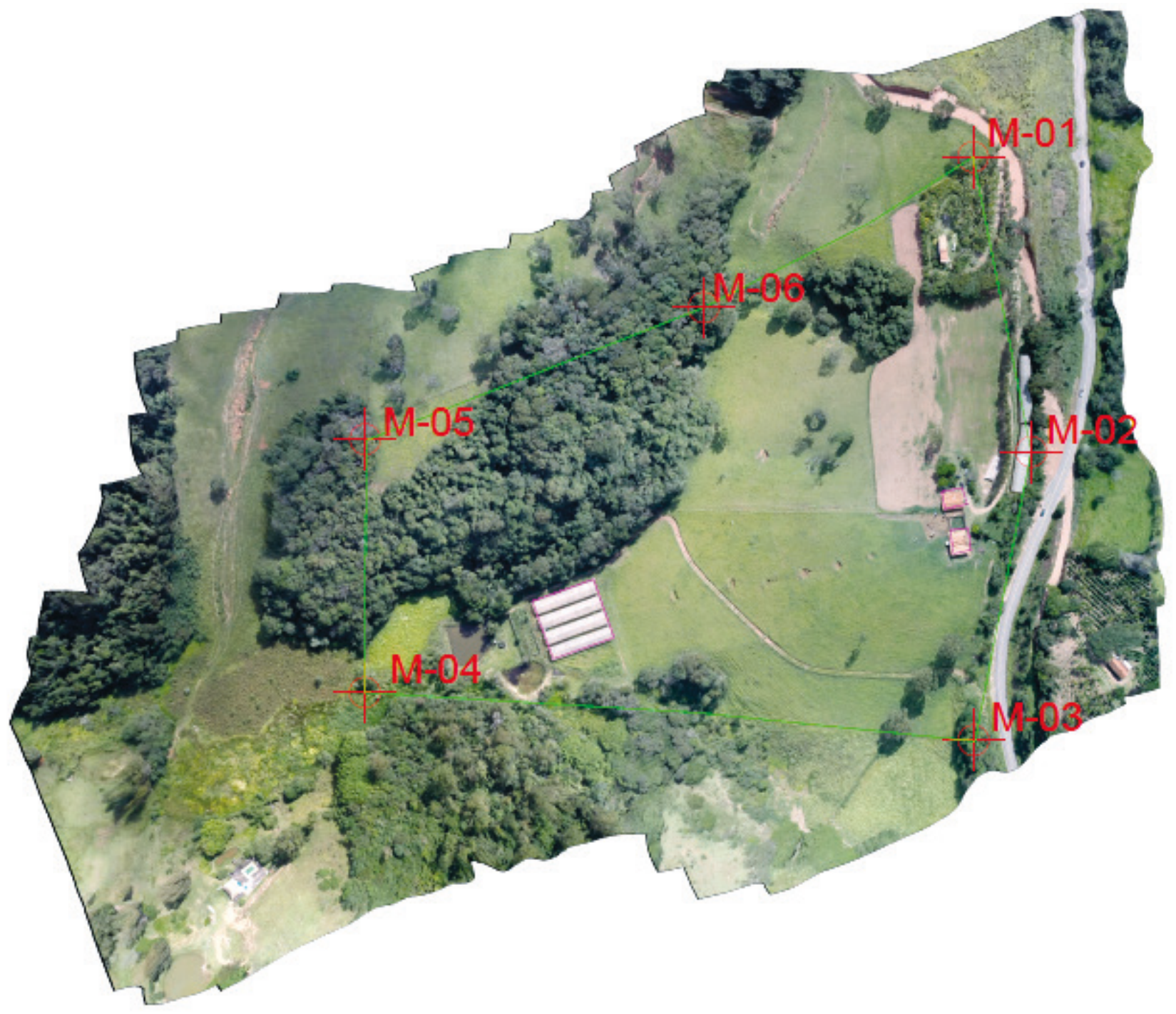

Fonte: Elaborada pelos autores (2016)

Tabela 1. Erro médio quadrático dos pontos de controle obtido na correção geométrica da imagem.

\begin{tabular}{cccc}
\hline \multicolumn{4}{c}{ Pontos de controle e seus respectivos RMS } \\
\hline Ponto & $\mathbf{E}(\mathbf{m})$ & $\mathbf{N}(\mathbf{m})$ & RMS Residual (pixel) \\
\hline M-01 & 362843,120 & 7530256,314 & 0,4831 \\
\hline M-02 & 362880,065 & 7530068,957 & 0,5670 \\
\hline M-03 & 362844,423 & 7529885,662 & 0,4123 \\
\hline M-04 & 362456,592 & 7529915,997 & 0,3235 \\
\hline M-05 & 362457,854 & 7530076,866 & 0,4230 \\
\hline M-06 & 362671,942 & 7530160,536 & 0,3720 \\
\hline & & RMS Total (pixel) & 2,5809 \\
\hline
\end{tabular}

Fonte: Elaborada pelos autores (2016)

Após o tratamento do produto obtido, foi realizado o processo de comparação entre as imagens, tendo como base os alvos naturais e artificiais (pontos com característica física pré-definida) 
das respectivas imagens, bem como o levantamento feito com estação total. Essa comparação é realizada em áreas de diferentes tamanhos e espaços, a fim de evitar resultados tendenciosos. Para comparações de áreas entre os dados da estação total e os dados da ortofoto, foi utilizado o Programa AutoCAD 2012,student version, que permite uma boa acuidade visual, além de uma visão real, dinâmica e precisa das áreas.

Nas imagens orbitais utilizou-se da plataforma do SISCAR para a obtenção das unidades de área, preservando o núcleo de estudo do trabalho. A plataforma permite obter diversos recursos de análises geométricas, tais como área, distância e paralela.

Para verificar a diferença entre áreas obtidas na ortofoto, imagem orbital e com a estação total foram selecionados três diferentes locais, a fim de evitar resultados tendenciosos (Figura 7, Figura 8 e Figura 9).

Figura 7. Área 1.

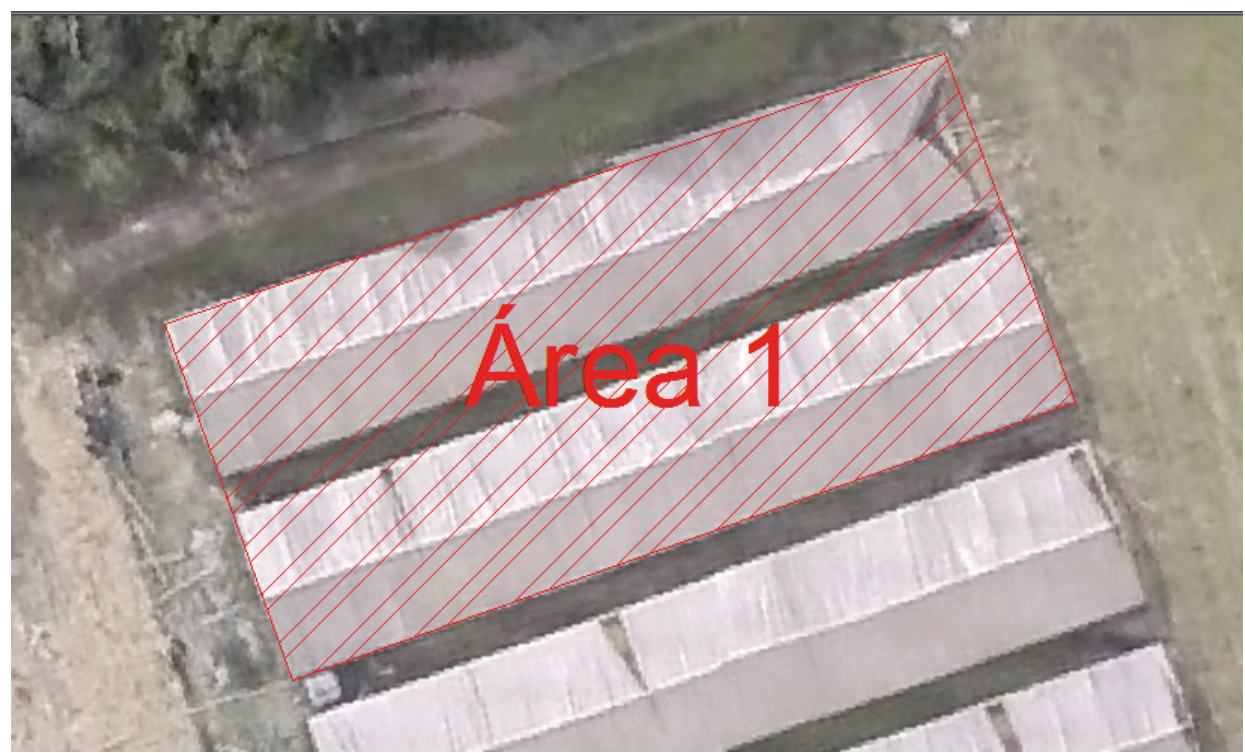

Fonte: Elaborada pelos autores (2016)

Figura 8. Área 2

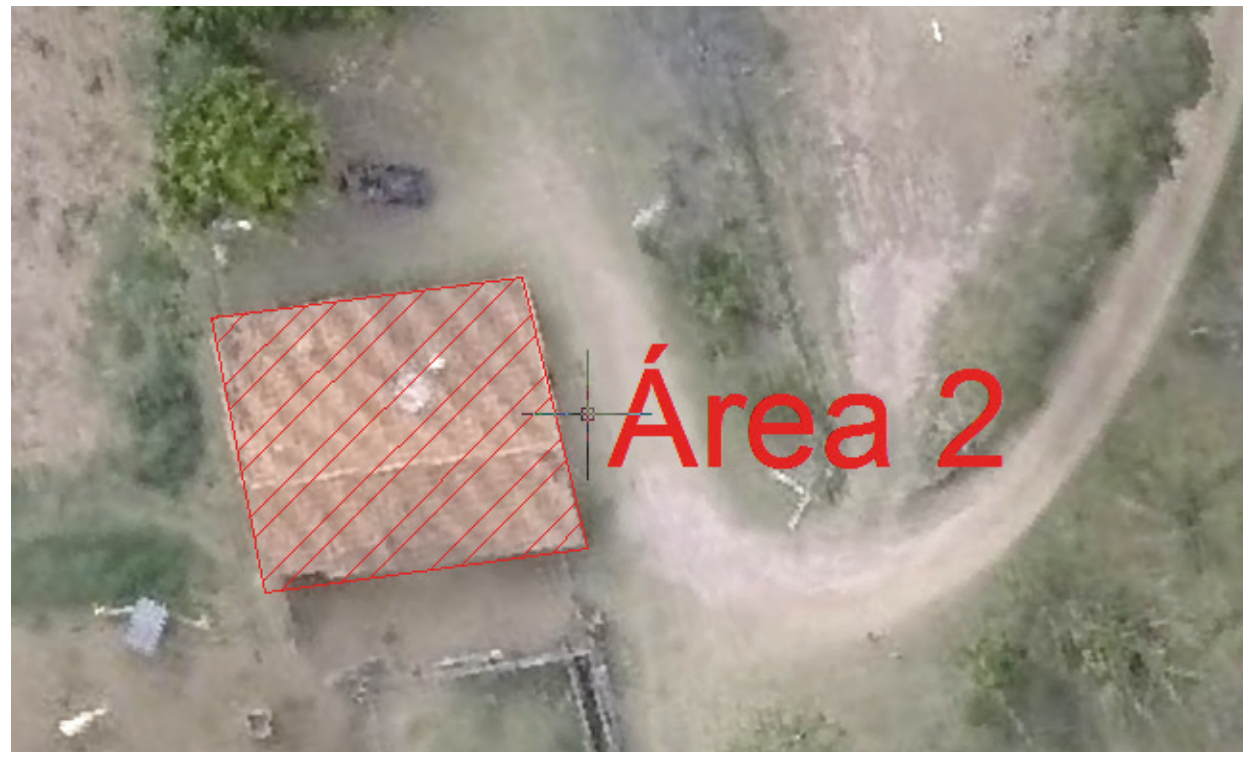

Fonte: Elaborada pelos autores (2016) 
Figura 9. Área 3.

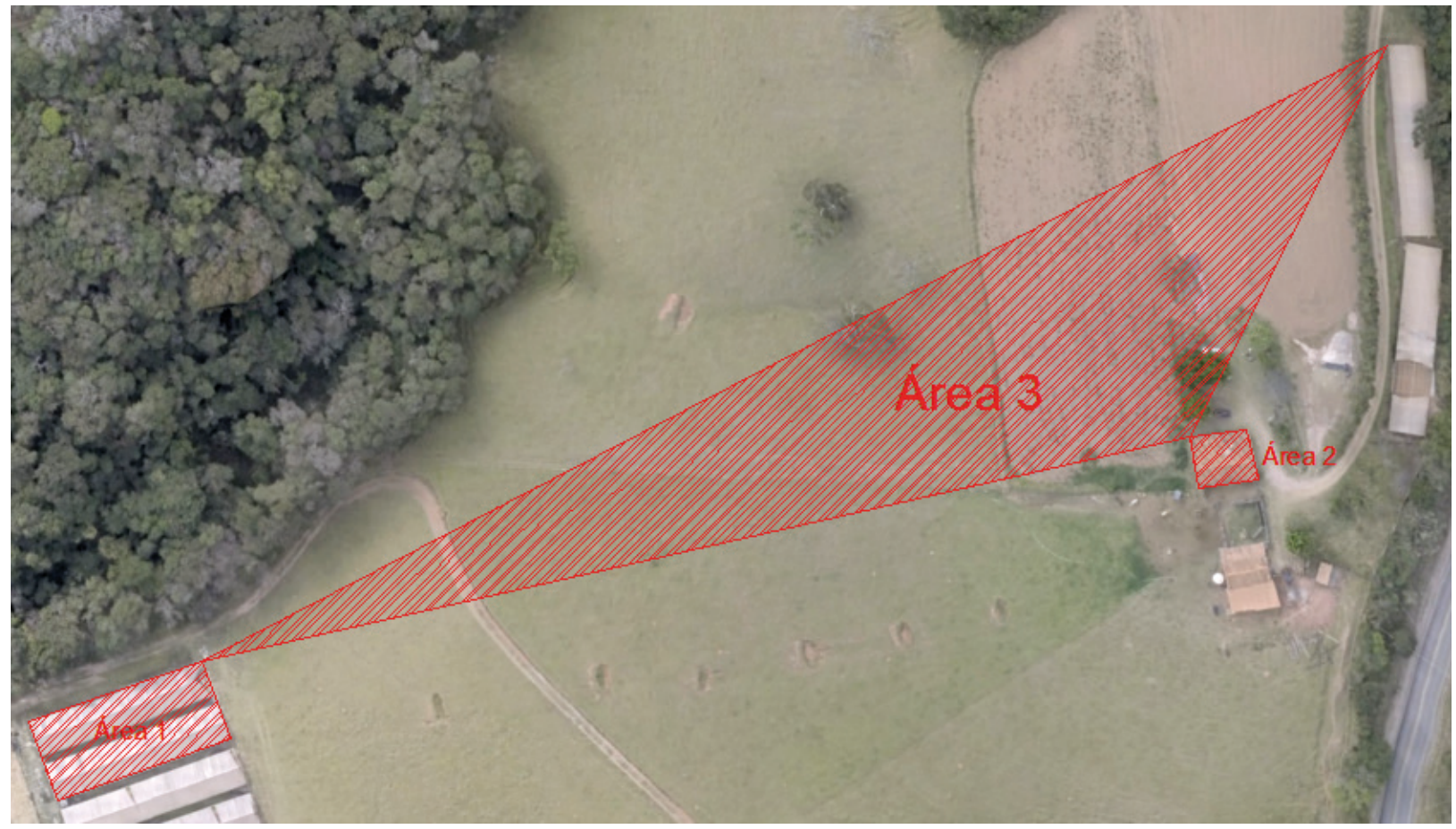

Fonte: Elaborada pelos autores (2016)

\section{Resultados e discussão}

Os resultados das análises e comparações entre a imagem orbital no sistema SISCAR e a ortofoto, com as áreas levantadas com a estação total, usando a plataforma CAD, podem ser observados na Tabela 2, abaixo.

Tabela 2. Áreas levantadas obtidas por diferentes métodos e seus respectivos desvios-padrão.

\begin{tabular}{cccc}
\hline \multirow{2}{*}{ Área } & & Formas de obtenção & \\
& Estação Total $\left(\mathrm{m}^{2}\right)$ & Ortoimagem com Correção $\left(\mathrm{m}^{2}\right)$ & Sistema offlinedo $\operatorname{CAR}\left(\mathrm{m}^{2}\right)$ \\
\hline $\mathbf{1}$ & $714,511 \pm 1,397$ & $713,578 \pm 5,167$ & $717,142 \pm 23,981$ \\
\hline $\mathbf{2}$ & $138,965 \pm 0,479$ & $135,717 \pm 3,016$ & $147,544 \pm 9,256$ \\
\hline $\mathbf{3}$ & $8248,742 \pm 4,782$ & $8321,261 \pm 10,615$ & $8786,246 \pm 43,448$ \\
\hline
\end{tabular}

Fonte: Elaborada pelos autores (2016)

De acordo com a Tabela 2, pode-se verificar que as áreas da ortofoto estão mais próximas das áreas da Estação total que representam a verdade de campo quando comparadas às obtidas com o sistema SISCAR, demonstrando, assim, que a ortofoto oriunda de um drone fotogramétrico é melhor em termos de precisão de área. Para consolidar a análise realizada, a Tabela 3 mostra em porcentagem a discrepância entre as áreas obidas pelas imagens (ortofoto e orbital) e estação total; observa-se que a área 3 apresenta maior discrepância com 6,516 \% no sistema SISCAR, enquanto a mesma área ortofoto apresenta uma discrepância de 0,879\%. Ainda pela Tabela 3, nota-se que todas as áreas obtidas pelo sistema SISCAR ficaram com maior discrepância quando comparadas com a ortofoto com correção. 
Tabela 3. Discrepância entre áreas em função da estação total.

\begin{tabular}{ccc}
\hline \multicolumn{3}{c}{ Discrepâncias entre áreas, em função da estação total } \\
\hline \multirow{2}{*}{ Área } & \multicolumn{2}{c}{ Formas de Obtenção } \\
\cline { 2 - 3 } & Ortofoto com correção (\%) & SISCAR (\%) \\
\hline $\mathbf{1}$ & 0,131 & 0,368 \\
\hline $\mathbf{2}$ & 2,337 & 6,173 \\
\hline $\mathbf{3}$ & 0,879 & 6,516 \\
\hline
\end{tabular}

Fonte: Elaborada pelos autores (2016)

Sabendo que o tamanho pixel no terreno (GSD) é de 0,0609 metros (obtido após cálculo do plano de voo),torna-se possível o cálculo da escala cartográfica do plano de voo. A Equação 2 mostra a relação para se chegar no resultado.

$$
\frac{1}{E}=\frac{0,2 \mathrm{~mm}}{\mathrm{RMS}^{*} \mathrm{GSD}}
$$

No processamento da Ortofoto, em sua correção geométrica, obteve-se um RMS de 2,5809 pixels para 6 pontos espalhados de forma homogênea na imagem, sendo 0,2 $\mathrm{mm}$ a menor acuidade visual possível cartograficamente; considerando o RMS 2,5906 e o GSD 0,609 m, obtém-se uma escala recomendável de 1/1.300.

Os testes foram realizados nas áreas centrais da imagem onde possuem uma maior variação na altitude do terreno. A ideia é realmente colocar a diferença de altitude como objeto de teste, uma vez que no plano de voo determina-se o GSD em função da mesma altitude média dos pontos do terreno. $\mathrm{Na}$ Tabela 4 pode se verificar a variação do GSD para diferentes alturas no terreno.

Tabela 4. variação do GSD em função da altura de voo média do terreno.

\begin{tabular}{ccccccccc}
\hline Altura média (m) & 80 & 90 & 100 & 110 & 120 & 130 & 140 & 150 \\
\hline GSD(cm) & 4,133 & 4,650 & 5,167 & 5,683 & 6,200 & 6,717 & 7,233 & 7,750 \\
\hline $\begin{array}{c}\text { Denominador } \\
\text { da Escala } \\
\text { Recomendada }\end{array}$ & 535 & 602 & 669 & 736 & 803 & 870 & 937 & 1004 \\
\hline
\end{tabular}

Fonte: Elaborada pelos autores (2016)

\section{Conclusões}

Na comparação entre imagens obtidas com o drone aerofotogramétrico e o sistema SISCAR, o primeiro apresentou resultados que superam a resolução espacial das imagens orbitais, proporcionando um produto com escala desejável ao controle ambiental necessário.

Acredita-se que na obtenção de informações espaciais admitem-se erros sistemáticos passíveis de ser modelados e corrigidos no decorrer da metodologia aplicada. Caso esses tenham sido negligenciáveis, quaisquers validações após a obtenção desses produtos são desnecessárias e equívocas. Portanto o sistema SISCAR apresenta diversos erros sistemáticos que foram negligenciados e estão acarretando equívocos na medida das áreas contidas na superfície do terreno.

$\mathrm{O}$ drone aerofotogramétrico pode ser recomendado para levantamento de pequenas áreas rurais devido ao tempo efetivo de voo ser limitado por sua bateria. Sua navegação deverá ser realizada em pequenas alturas de voo. Logo, grandes desníveis sobre o terreno (montanhas) deverão ser considerados para o cálculo final do GSD, o que influenciará diretamente na escala final do produto desejado. 


\title{
Agradecimentos
}

Ao IFSULDEMINAS - Campus Inconfidentes pela estrutura para os experimentos.

\section{Rural Environmental Registry using aerophotogrammetric drone image}

\begin{abstract}
The Rural Environmental Registry is an important strategic database for environmental management in our country. This study aims to compare the accuracy of the orbital image available to the rural environmental registry with an orthophoto obtained from an aerophotogrammetric drone; the cartographic product obtained from total station was the uncertainty parameter. The orthophoto showed better results than the orbital image. Both of them were analyzed by comparing homologous areas in the images, of different sizes and positions, in both map products. This result can justify the purchase of a more reliable product for environmental control in our country, especially in small rural areas, given that the territorial portion is extensive and not homogeneous.
\end{abstract}

Keywords: Applied photogrammetry. Rural properties. Environment.

\section{Referências}

ANDRADE, J.B. Fotogrametria. Curitiba: SBEE, 2003.

BRASIL. Siscar. Governo Federal.CAR: Cadastro Ambiental Rural. 2016. Disponível em: <http://www.car.gov.br/>. Acesso em: 09 mar. 2016.

BRASIL. Ministério do Meio Ambiente. Cadastro Ambiental Rural (CAR). 2015. Disponível em: <http://www.mma.gov.br/desenvolvimento-rural/cadastro-ambiental-rural >. Acesso em: 10 ago. 2015.

BROWN, D. Descentering Distortion of Lenses. Photogrammetric Engineering, v. 32, n. 3, p. 444-462, 1966.

COELHO, L.; BRITO, J. N. Fotogrametria digital. Rio de Janeiro: Editora da Universidade do Estado do Rio de Janeiro, 2009. 196 p.

SERVIÇO FLORESTAL BRASILEIRO (Brasil). Ministério do Meio Ambiente. Boletim Informativo: Janeiro de 2016 CAR. 2016. Disponível em: <http://www.florestal.gov.br/cadastroambientalrural/ index.php?option $=$ com_docman\&task $=$ doc_download\&gid $=2973 \&$ ltemid $=303>$. Acesso em: 08 mar. 2016.

SERVIÇO FLORESTAL BRASILEIRO (SFB). Números do Cadastro Ambiental Rural. 2015. Disponível em: <http://www.florestal.gov.br/cadastro-ambiental-rural/numeros-do-cadastro-ambiental-rural>. Acesso em: 11 ago. 2015.

\section{Histórico editorial:}

Submetido em: 11/03/2016

Aceito em: 20/06/2016 
Como citar:

$\underline{A B N T}$

SILVA, J. E. C. F. da; BOTELHO, M. F. Cadastro Ambiental Rural utilizando imagem de drone aerofotogramétrico. Revista Agrogeoambiental, Pouso Alegre, v. 9, n. 2, p. 73-83, abr./jun. 2017. Doi: http://dx.doi. org/10.18406/2316-1817v9n22017963

APA

SILVA, J. E. C. F. da \& BOTELHO, M. F. (2017). Cadastro Ambiental Rural utilizando imagem de drone aerofotogramétrico. Revista Agrogeoambiental, Pouso Alegre, 9 (2), 73-83. Doi: http://dx.doi. org/10.18406/2316-1817v9n22017963

$\underline{\text { ISO }}$

SILVA, J. E. C. F. da; BOTELHO, M. F. Cadastro Ambiental Rural utilizando imagem de drone aerofotogramétrico. Revista Agrogeoambiental, 2017, vol. 9, n. 2, pp. 73-83. Eissn 2316-1817. Doi: http:// dx.doi.org/10.18406/2316-1817v9n22017963

VANCOUVER

Silva JECF, Botelho MFS. Cadastro Ambiental Rural utilizando imagem de drone aerofotogramétrico. Rev agrogeoambiental. 2017 abr/jun; 9(2): 73-83. Doi: http://dx.doi.org/10.18406/2316-1817v9n22017963 